\title{
Is solar variability reflected in the Nile River?
}

\author{
Alexander Ruzmaikin, ${ }^{1}$ Joan Feynman, ${ }^{1}$ and Yuk L. Yung ${ }^{2}$ \\ Received 1 May 2006; revised 5 July 2006; accepted 9 August 2006; published 11 November 2006.
}

[1] We investigate the possibility that solar variability influences North African climate by using annual records of the water level of the Nile collected in 622-1470 A.D. The time series of these records are nonstationary, in that the amplitudes and frequencies of the quasi-periodic variations are time-dependent. We apply the Empirical Mode Decomposition technique especially designed to deal with such time series. We identify two characteristic timescales in the records that may be linked to solar variability: a period of about 88 years and one exceeding 200 years. We show that these timescales are present in the number of auroras reported per decade in the Northern Hemisphere at the same time. The 11-year cycle is seen in the Nile's high-water level variations, but it is damped in the low-water anomalies. We suggest a possible physical link between solar variability and the low-frequency variations of the Nile water level. This link involves the influence of solar variability on the atmospheric Northern Annual Mode and on its North Atlantic Ocean and Indian Ocean patterns that affect the rainfall over the sources of the Nile in eastern equatorial Africa.

Citation: Ruzmaikin, A., J. Feynman, and Y. L. Yung (2006), Is solar variability reflected in the Nile River?, J. Geophys. Res., 111, D21114, doi:10.1029/2006JD007462.

\section{Introduction}

[2] Knowledge of the water level of the Nile River was critically important for agriculture and the preservation of temples in Egypt throughout its history. Measurements of these levels have been carried out since the times of the pharaohs [Hurst, 1952; Bell, 1970]. Shakespeare mentioned a Nilometer tower used in the measurement of water level: "Thus do they, sir. They take the flow o" the Nile by certain scales i' the pyramid; they know by the height, the lowness, or the mean, if dearth or foison follows. The higher Nilus swells the more it promises" (Antony and Cleopatra, Act II Scene VII). Annual records converted into metric units are available for 622-1470 A.D. [Toussoun, 1925]. Such direct measurements are rare if not unique in long-term climatological studies, which usually rely on indirect measurements and proxies. Here we use these data to investigate the possible influence of solar variability on the Earth's climate. The Nile records have been previously examined by various spectral methods [Hameed, 1984; De Putter et al., 1998; Kondrashov et al., 2005]. Specific periodicities, such as 7, 12, 19, 64, 76, 256 years were reported. Spectral methods based on Fourier decomposition contain an underlying assumption that the frequency content is independent of time, i.e., that the time series is stationary. However, the Nile water level records,

\footnotetext{
${ }^{1}$ Jet Propulsion Laboratory, California Institute of Technology, Pasadena, California, USA.

${ }^{2}$ Department of Geological and Planetary Sciences, California Institute of Technology, Pasadena, California, USA.

Copyright 2006 by the American Geophysical Union. 0148-0227/06/2006JD007462
}

as pointed out by the cited researches are nonstationary in that no strict periodicities or oscillations at constant amplitudes are present. To better handle these data we apply the Empirical Mode Decomposition (EMD) technique, which is especially designed for analyses of nonstationary, nonlinear time series [Huang et al., 1998]. The EMD represents the data as the sum of a small number of orthogonal empirical modes that have time-variable amplitudes and instantaneous frequencies. Each mode has a symmetric envelope defined by the local maxima and minima so that its mean amplitude is zero everywhere. Its mean period can be determined by counting the number of peaks (maxima). The instantaneous frequencies as functions of time are found for each mode with the help of the Hilbert transform. In comparison, the Fourier decomposition presents time series as the sum of harmonics with fixed frequencies and amplitudes. This usually requires many harmonics and works well when the same frequencies are present all times, i.e., for stationary processes. The EMD, which captures the nonstationary spectral content of the data, is similar to the wavelet decomposition. However the wavelet decomposition employs a preset basis function (such as the Morlet wavelet). In contrast, the EMD basis is changing in time to adapt to the actual variability of the data [Huang et al., 1998].

[3] The water of the Nile at Rawdah Island in Cairo, where the records were taken, is supplied predominantly by the Blue Nile (plus by the river Atbara) whose main source is Lake Tana in Ethiopia, and by the White Nile whose main source is Lake Victoria in eastern equatorial Africa. The Blue Nile source accounts for about $90 \%$ of the levels in times of floods. These floods strongly reflect the high-frequency variability of rainfall in Ethiopian 

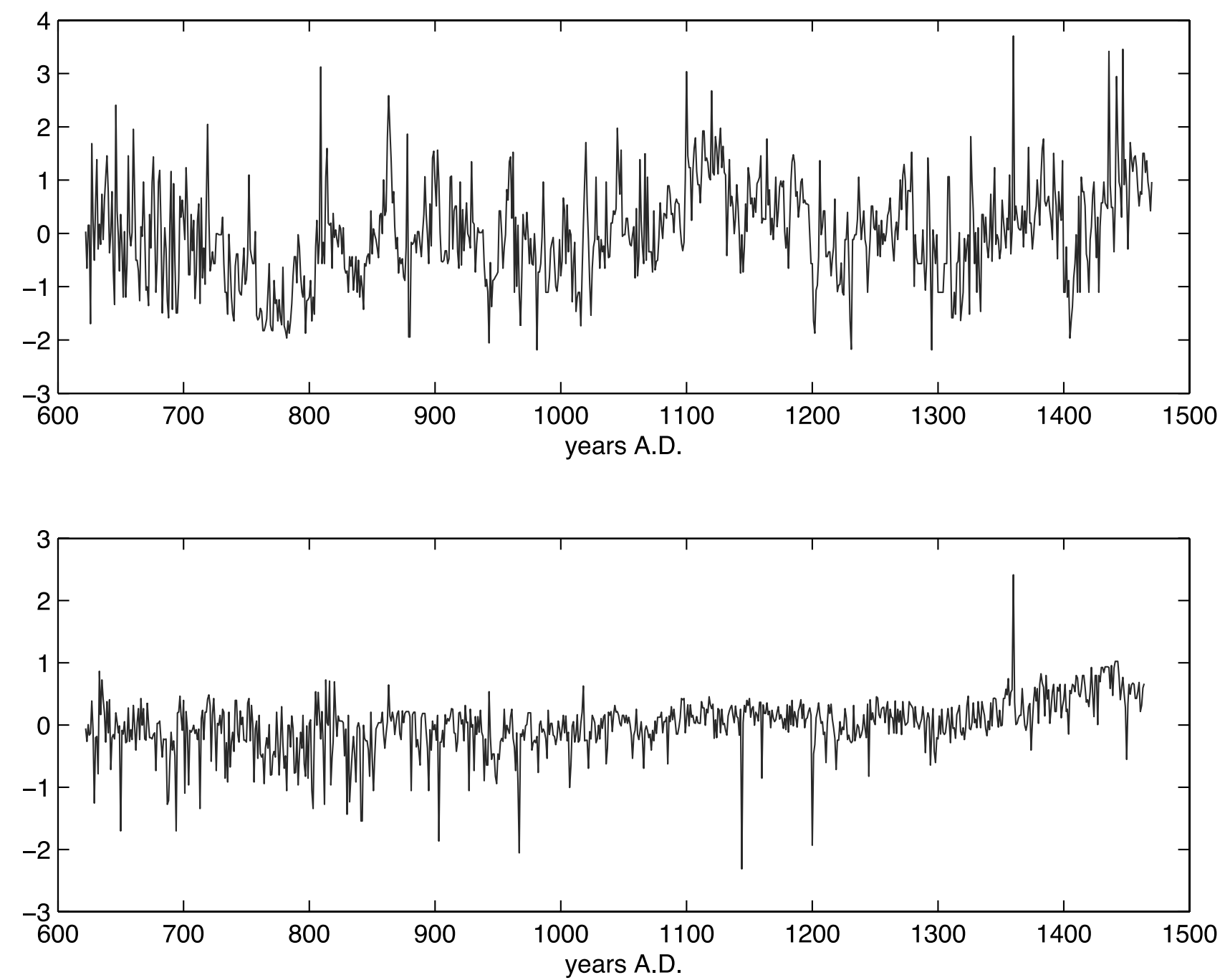

Figure 1. (top) Low-water anomalies and (bottom) high-water anomalies records of the Nile River in 622-1470. The anomalies are defined by subtracting mean values for the whole period. The measurement were taken by the Rawdah Island Nilometer in Cairo.

highlands caused by localized convective storms and excursions of the Intertropical Convergence Zone [Nicholson, 2000; Sene et al., 2001]. In contrast, the White Nile is critically responsible (at about $83 \%$ ) for maintaining the Nile flow during the low-water levels in the dry (October-April) period [Hurst, 1952]. The low water levels show a rich low-frequency variability, which is rooted in the variability of Lake Victoria. Low-frequency variability is also seen in the high water levels. It has been suggested that the high-frequency peaks in the Nile records are linked to El Niño Southern Oscillation (ENSO) events [Rind, 1996]. Low-frequency variations were suggested as possibly related to solar forcing [Hameed, 1984; Loutre et al., 1992].

[4] The low-water and high-water anomaly records of the Nile River in 622-1470 A.D are shown in Figure 1.

[5] In section 2, we carry out the data analysis of these water level records. In section 3 , we analyze the concurrent aurora data that serve as a proxy for solar variability. In section 4 we discuss a possible link between solar vari- ability and the sources of the Nile. Section 5 summarizes our conclusions.

\section{Variability of the Nile Water Levels}

[6] The results of application of the Empirical Mode Decomposition method to the Nile's low-water and highwater levels are presented in Figures 2 and 3. Figures 2 and 3 show the mode amplitudes and distributions of their instantaneous frequencies. The peaks of the frequency distributions are in a general agreement with the frequencies found by earlier authors. For example, the maximum of the frequency distribution of the second mode (right, first panels) is in agreement with the $(7 \text { year })^{-1}$ quasi-periodicity thus supporting a major result of Kondrashov et al. [2005]. (To our judgment, however, the 7-year period does not quite fit the biblical story of droughts, because "seven years of drought" followed by "seven years of plenty" corresponds to a 14-year period.) These authors also found 64-year and 256-year periods, seen in 5th and 7th modes. Although the frequency distribution for mode 3 may be associated with 

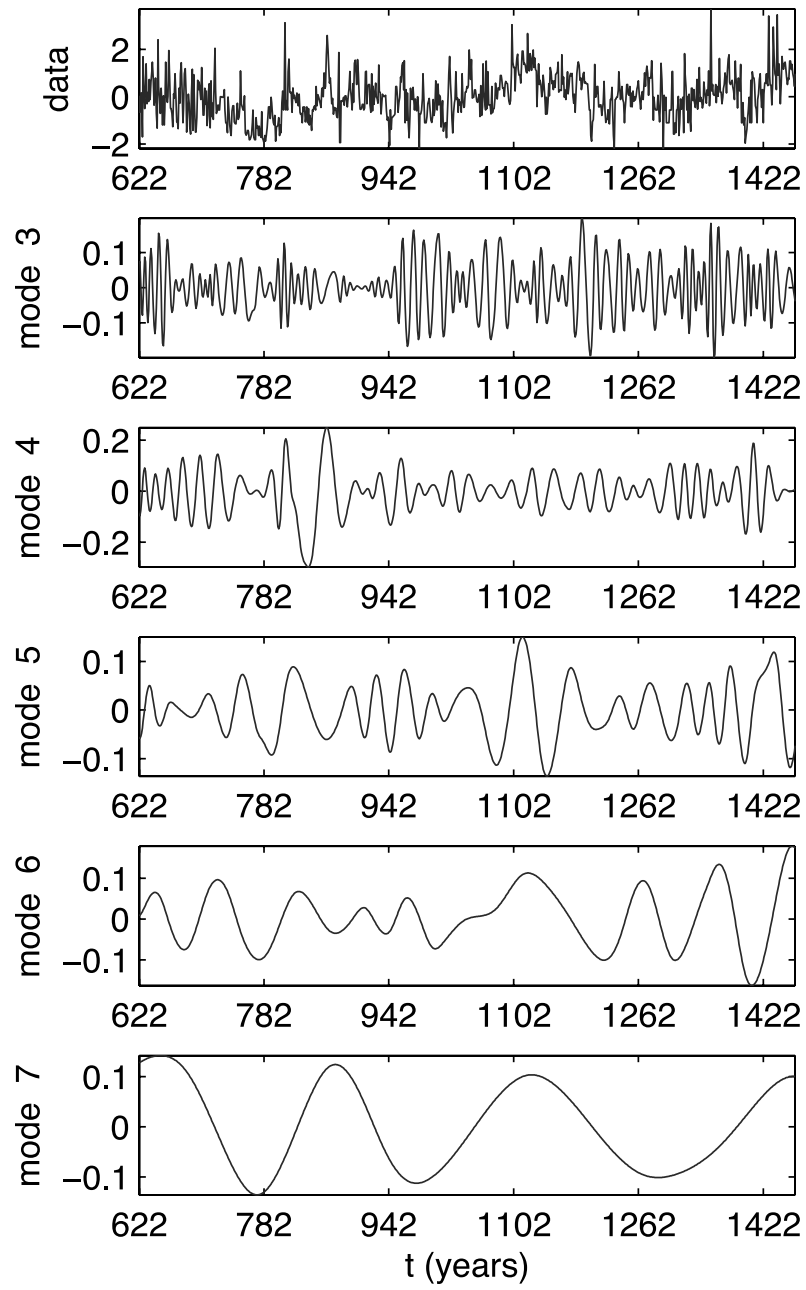
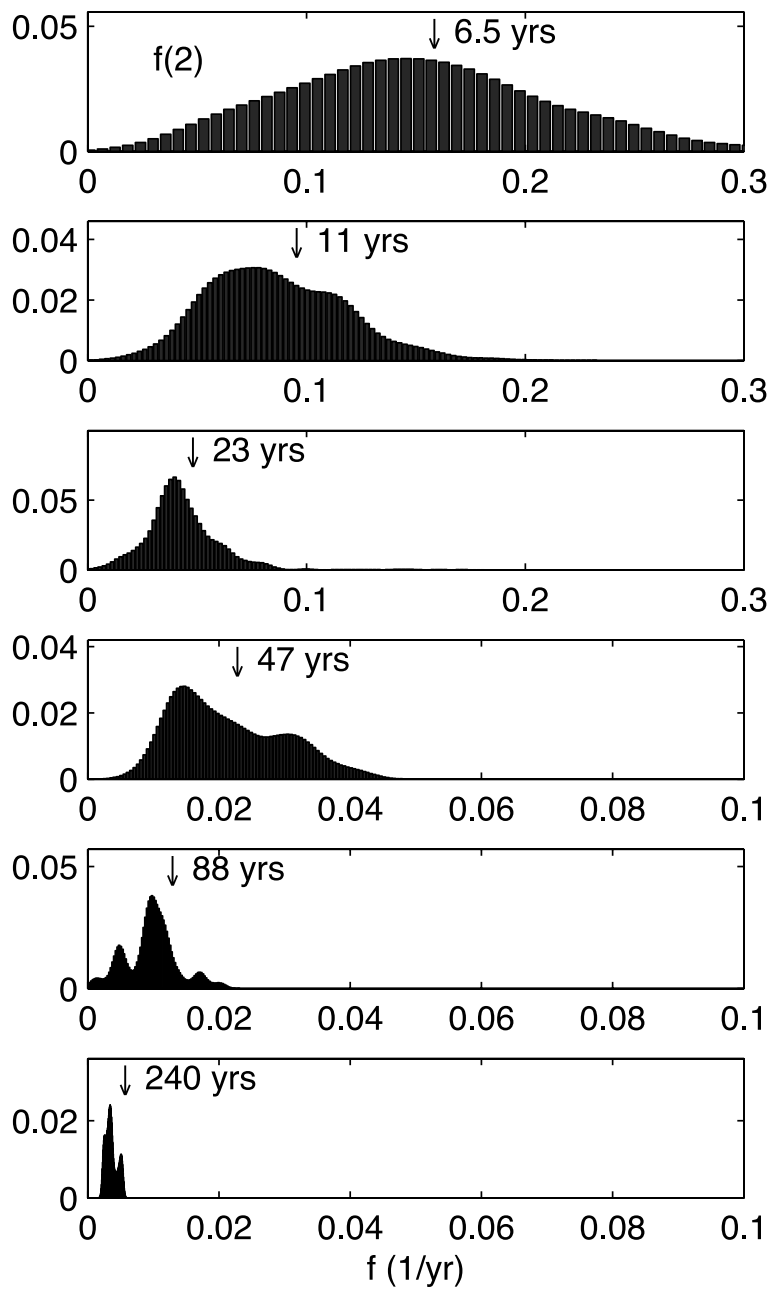

Figure 2. (left) Low-water record 622-1470 A.D. normalized to its maximum value (first panel) and its EMD modes 3-7. (right) Distributions of the instantaneous frequencies for mode 2 (first panel) and for modes 3-7. The frequency distributions are calculated with the kernel method that improves standard histograms (available in Matlab library). The numbers with arrows show the mean periods of the modes. Standard deviations of the shown distributions for modes $2-7$ are 3, 4, 9, 18, 42, and 67 years, respectively.

the 11-year solar cycle it does not concentrate strongly around this period. The 24 -year variation of mode 4 may be associated with the similar variability seen in the North Atlantic Oscillation (NAO). This variability has been reported in dendrochronological reconstructions of the NAO [Cook et al., 1998]. A similar 24-year variation is found in the principal component of the first Empirical Orthogonal Function of extratropical North Atlantic SST in the 20th century (N. Heavens and X. Jiang, private communication, 2006). This natural variability could be a cause of the change in cloud fraction that need to be taken into account in the evaluation of greenhouse effect [Cess and Udelhofen, 2003].

[7] Why does the mode corresponding to the 11-year variation in Figure 2, which characterizes the White Nile variability, have a wide spread of frequencies? A possible explanation of the differences in the response to the 11-year cycle of the White Nile flow can be inferred from water balance studies [Nicholson, 2000; Sene et al., 2001]. The White Nile starts as an outflow from Lake Victoria and then is affected by a chain of smaller lakes and swamps, the largest of which is the Sudd swamp. The lake level is balanced by precipitation, minus evaporation, plus contributions of tributary inflows, minus the White Nile outflow. This outflow is a nonlinear function of the lake water level that in turn depends on immediate rainfall and a delayed runoff from the watershed area. The chain of lakes and swamps further down the river induces damping and time delays for the White Nile. Thus, if the lake level suddenly rises, because of a heavy rainfall, and then the net basin supply returns to its previous value, the lake level decreases exponentially to its equilibrium state but the White Nile behaves differently. Numerical modeling [Sene et al., 2001] showed that if the lake level were increased by $1 \mathrm{~m}$, the characteristic half-lifetime constant for the White Nile outflow restoration would be about 8 years. Note that there is a second peak near about 8 years in the frequency distribution for this mode (Figure 2), and no such peak is seen in the frequency distribution for this mode for the highwater levels (Figure 3). That could be why the changes in 

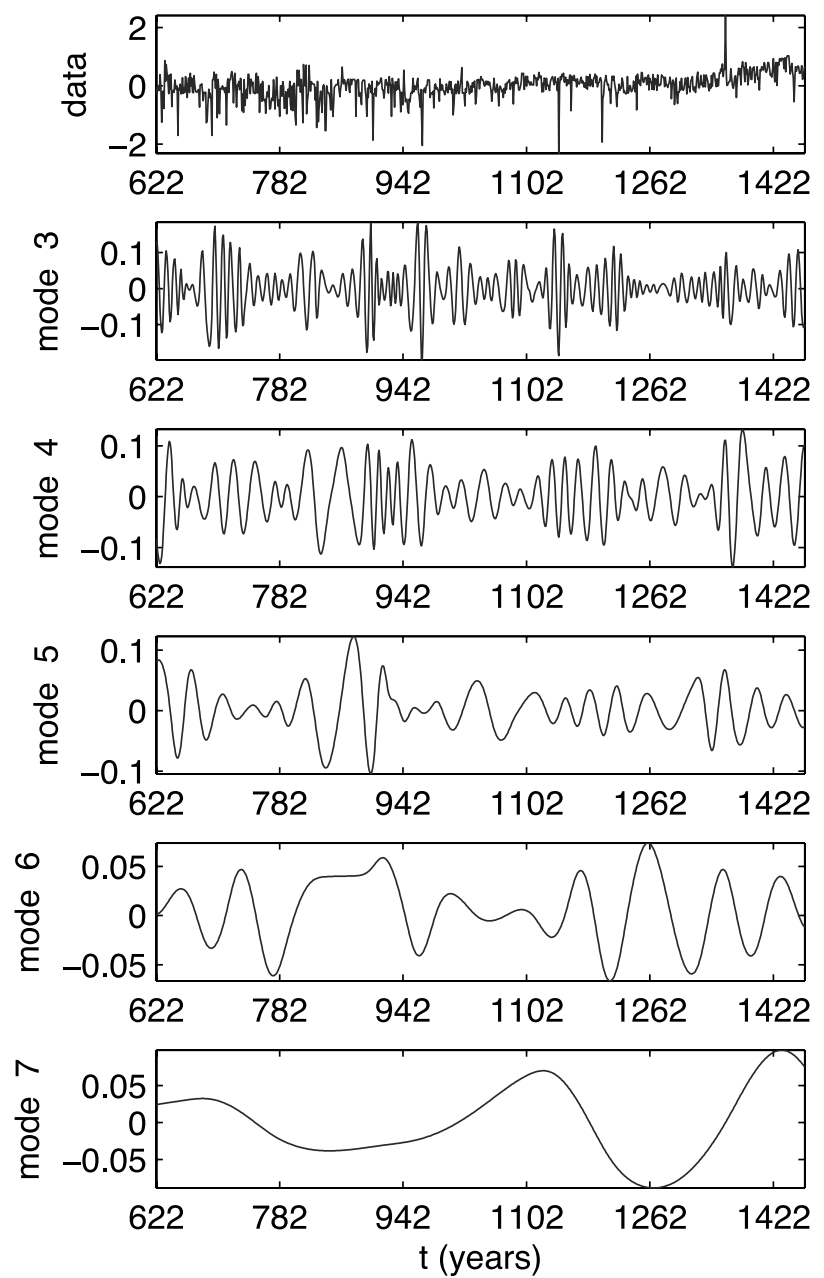
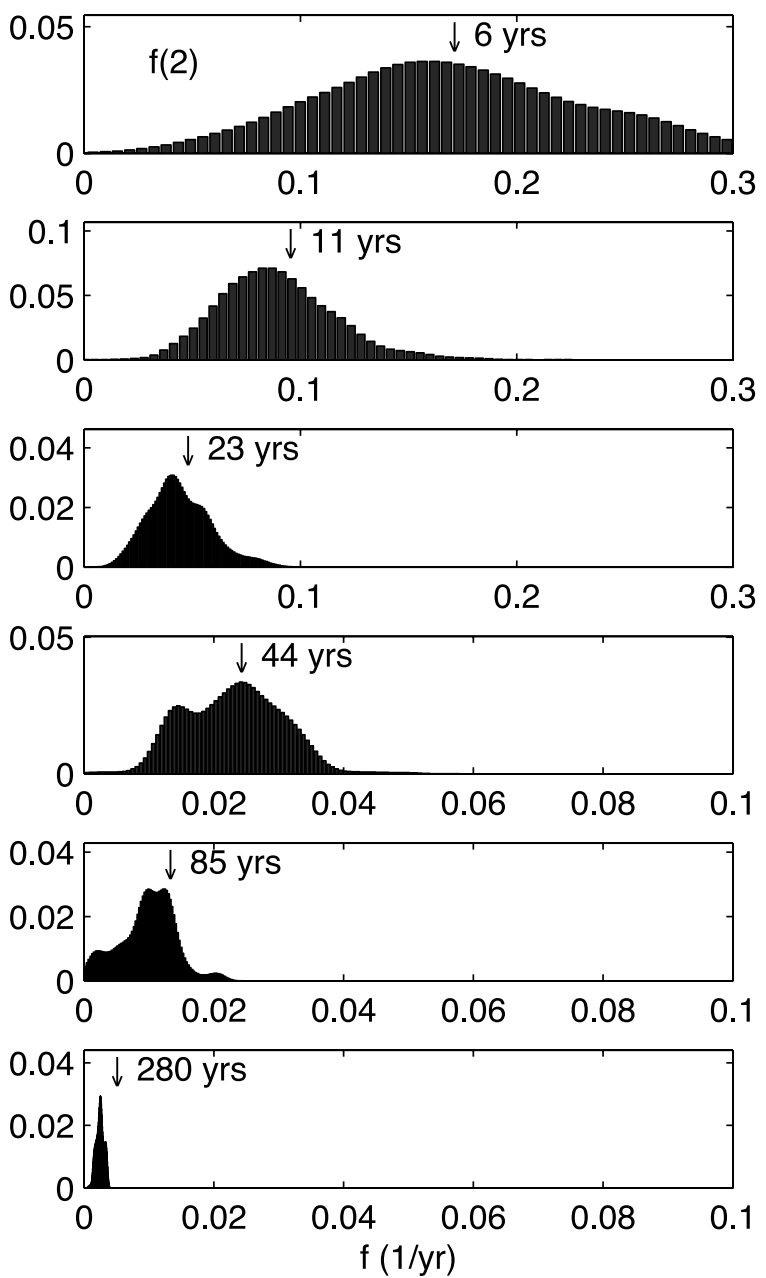

Figure 3. Same as Figure 2 for the high-water record 622-1470 A.D. Standard deviations of the shown distributions for modes $2-7$ are $2,4,7,14,45$, and 97 years, respectively.

Lake Victoria and the White Nile are different on timescales apparently affecting the 11-year variability. The damping effects are not important on timescales longer than 11-year cycle, such as 88-year and 260-year timescales.

[8] The most interesting result is the dominance of the near 88-year periodicity in both records, as seen in the vertical scale of its frequency distribution. This suggests a relation to solar variability, see the next section. The peak around 260 years, is possibly related to periodicities identified in the ${ }^{14} \mathrm{C}$ record and attributed to solar variability [Stuiver and Brauzanias, 1989].

[9] How statistically significant are the identified modes? In principle, nonstationary cycles could conceivably appear in a pure noise time series sampled over a finite interval. The data no doubt contain noise resulting from measurement errors (white noise) and physical processes (white and red noise). The interpretation of the red noise, usually present in many geophysical records, is a challenging task because this type of "noise" might be an intrinsic part of the processes responsible for the observed variability and, if so, can be treated as a signal. It has been shown that the EMD modes of the white noise are all normally distributed and their energy density (the sum of squared amplitudes) has a mean value directly related to their mean period, and the energy density spread function increases with the mean period [Wu and Huang, 2004]. Similar distributions for the energies of the EMD modes constructed for fractional (red) noises, the correlation level of which is characterized by the Hurst exponent $H$, have been found [Flandrin and Goncalves, 2004]. The statistical significance of the modes obtained from the data thus can be tested against white and fractional noise. Here we estimate the statistical significance of the modes presented in Figures 2 and 3 for two cases: $H=$ 0 corresponding to white noise, and $H=0.8$ corresponding to a strongly correlated fractional noise associated with Nile records [Feder, 1988]. (We also generated red noise time series using an iterative procedure simulating a random process, which depends only on its own immediate past plus a random component [Gilman et al., 1963]: $x_{n}=$ $\rho x_{n-1}+\rho_{n}$, where $\rho$ is the correlation coefficient. The EMD modes of these time series depend on the correlation coefficient $\rho$ approaching to the white noise modes when $\rho \rightarrow 0$. The conclusions for the correlation coefficient as in the underlying Nile river records are similar to those made below for the fractional noise defined by the Hurst exponent.) (Note that the Hurst exponent for the low-water 

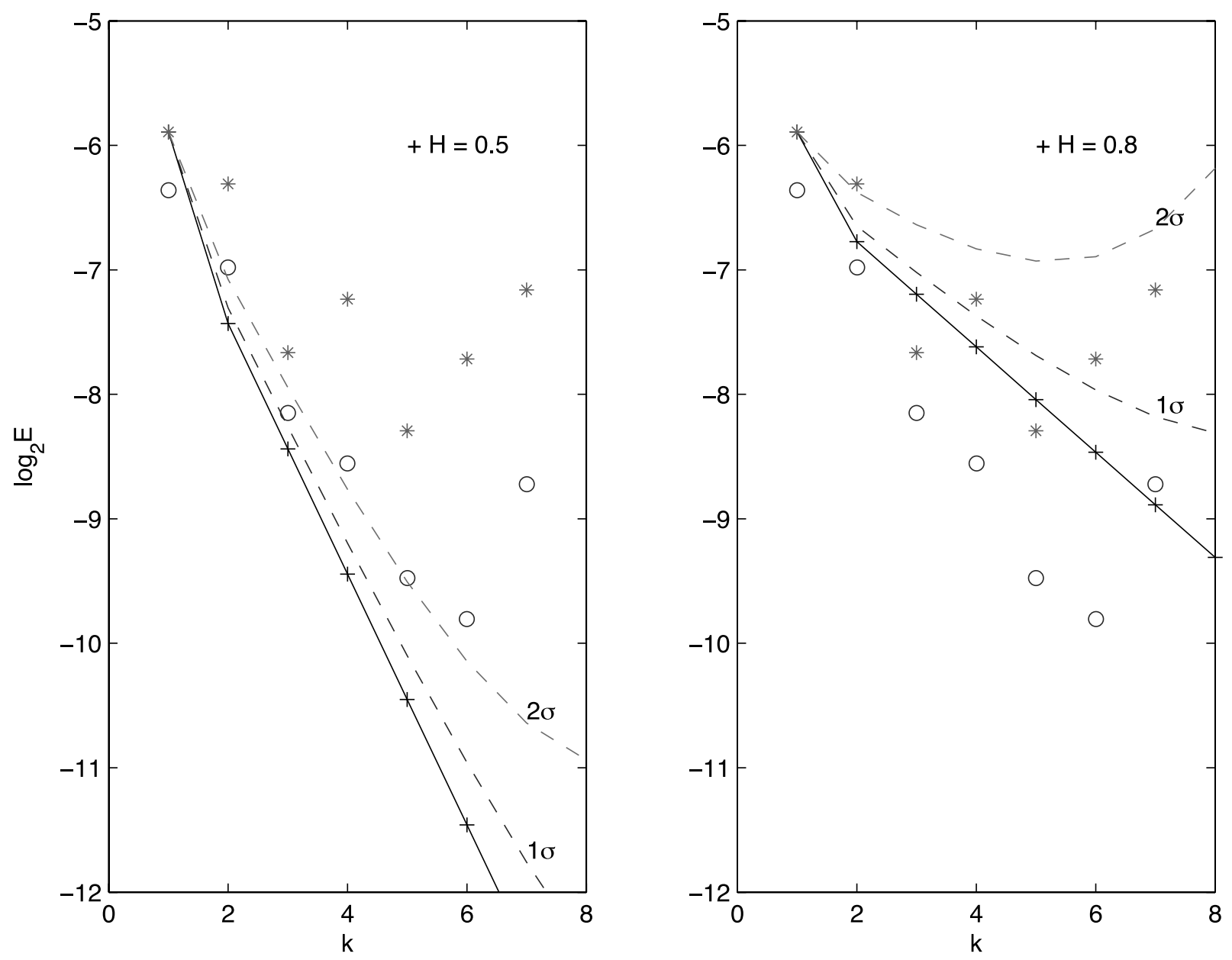

Figure 4. Evaluation of the statistical significance of the modes numbered by k. (left) White noise $(H=0)$ and (right) a strongly correlated red noise with $H=0.8$. The solid line with crosses is constructed for the noise modes. The dashed lines are the energy spread functions for these modes at $1 \sigma$ and $2 \sigma$ levels. The asterisks and circles mark the energy densities E for the low and high water levels, respectively.

record is a bit higher than 0.8. This slightly lowers the statistical significance of the low-water modes.) Figure 4 shows the distribution of energy density for the low and high water data and for the white and fractional noise. The dashed lines outline the 1 and $2 \sigma$ confidence limits obtained by the method suggested by Flandrin and Goncalves [2004] based on the work for white noise by $W u$ and Huang [2004]. We see that the 88-year and 260-year modes are statistically significant at $2 \sigma$ level against the white noise and at $1 \sigma$ level against the strongly correlated fractional noise (with the exception of the last mode for the high waters).

\section{Concurrent Aurora Record}

[10] For almost 1,500 years aurora appearances at mid latitudes in Europe and Asia were carefully recorded because of the belief that they portended important events such as droughts and deaths of kings. These records have been collected and evaluated for accuracy (see Siscoe [1980] for a comprehensive review of sources of auroral data). Auroras are caused by very high speed solar wind disturbances produced in association with fast coronal mass ejections and major solar flares. The rate of auroras is strongly correlated with the sunspot number (correlation coefficient 0.85, see Feynman [1988]) and thus is an excellent proxy for solar variability.

[11] To evaluate a connection between the peak of the 88-year mode of the Nile records and the solar variability we applied the EMD to a record of the number of auroras reported per decade in the Northern Hemisphere in 620-1440 A.D. as given by Feynman and Fougere [1984]. The decadal auroral record shows a strong spectral line at $88.4 \pm 0.7$ years. This periodicity arises as the amplitude modulation of the 11-year solar cycle, and is referred to as the "Gleissberg" cycle in the sunspot studies. Note, however, that the duration of the Gleissberg cycle determined with sunspot data available for the past few centuries varies between 55-100 years while for the time interval $>800$ years considered in this paper (with auroras used as a proxy for solar variability) it was close to 88 years. Figure 5 shows that aurora's EMD mode 2 has a frequency distribution peaked around 88 -years. The phases of this variation is not well deter- 

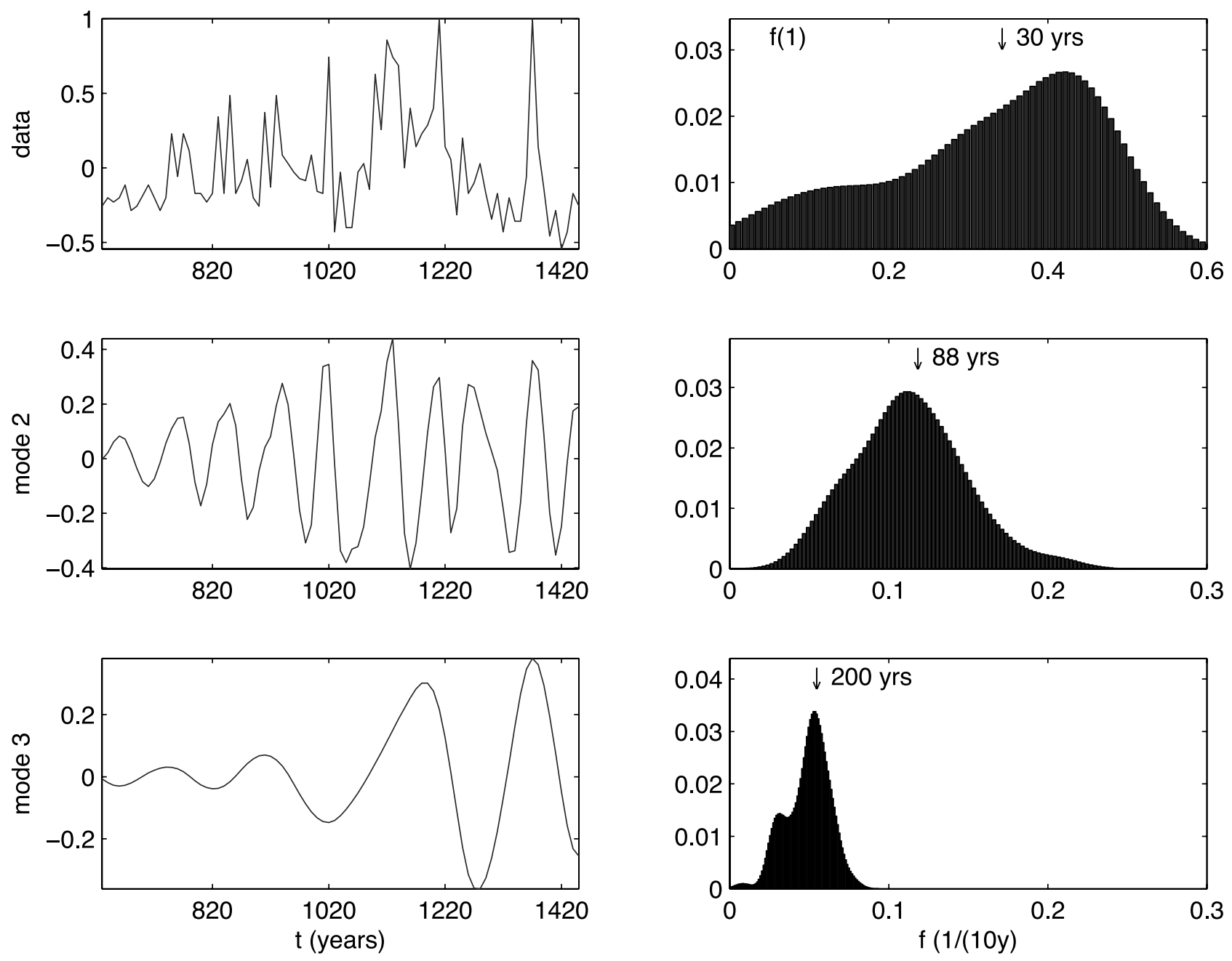

Figure 5. (left) Rate of auroras normalized to its maximum value (first panel) and its EMD modes 2-3. (right) Distributions of the instantaneous frequencies for mode 1 (first panel) and modes $2-3$ shown on the right. The numbers with arrows show the mean periods of the modes. Standard deviations of the shown distributions for modes $2-3$ are 10,30 , and 50 years, respectively.

mined in the data because each data point is a collection of human observations within 10 years.

\section{Discussion of Possible Mechanisms}

[12] Both sources of the Nile, Lake Victoria and Lake Tana, are fed by precipitation in eastern equatorial Africa. Thus the low-water level of the White Nile in the extended winter (October-April) is largely determined by Lake Victoria, which drains $10 \%$ of its water into this river [Sene et al., 2001; Tate et al., 2005]. Thus the key question is "How does solar variability influence the rainfall in eastern equatorial Africa?"

[13] The rainfall in eastern equatorial Africa shows interannual variability coherent throughout the region [Nicholson, 2000]. On the annual timescale the Lake Victoria variability follows the rainfall variability with the most prominent variation at a timescale of 5-6 years typical for the ENSO [Mistry and Conway, 2003]. On the seasonal scale the rainfall pattern is bimodal with more variability accounted for by conditions during so called short rains in
October-November-December (24.4 mm/season) than during the long rains in March-April-May (19.2 mm/season) [Mistry and Conway, 2003]. It has been argued [Black et al., 2003] that extreme short rains are associated with the largescale sea-surface temperature (SST) meridional gradient across the Indian Ocean. The positive gradient weakens the westerly wind that normally transports moisture away from the African continent toward the Indian Ocean. Climatological mean value of the gradient is near zero in times of short rains. In particular, this allows for strong El Niño Southern Oscillation (ENSO) events to force the weak meridional SST gradient and thus the East African rainfall.

[14] It is less clear how solar variability could affect the Indian Ocean Dynamics related to the East African rainfall. One possibility is that the large-scale SST gradient in the Indian Ocean could be affected by the major anomalous pattern induced by the North Atlantic Oscillation (NAO) [Hurrel, 1996]. Kodera [2003] found that during low solar activity winters the NAO signal is confined to the Atlantic sector, while during the high solar activity winters the NAO-related anomalies extend over the whole Northern 
Hemisphere. Also during high solar activity the NAO prolongs its influence into spring-summer season [Ogi et al., 2003]. The relationship between the NAO and solar variability can be understood by taking into account that the NAO is closely related to the Northern Annular Mode (NAM) that extends from sea level to the top of the stratosphere [Thompson and Wallace, 1998; Baldwin and Dunkerton, 1999]. Analysis of the 1958-1997 NCEP Reanalysis data showed that the NAM is statistically significantly affected by the solar variability [Ruzmaikin and Feynman, 2002]. Recently Hameed and Lee [2005], who also used the NCEP data, reported that a greater fraction of stratospheric perturbations penetrate to the Earth's surface during solar maximum conditions than during solar minimum conditions. Strong variations of the solar UV flux in the stratosphere modulate the ozone and temperature gradients influencing the interaction of the mean zonal wind and planetary waves that generate the NAM [Lean and Rind, 1998; Limpasuvan and Hartmann, 2000]. It has also been shown that the reconstructed sensitivity of the sea level temperature to long-term solar forcing in the Northern Hemisphere is in a very good agreement with the empirical temperature pattern corresponding to changes of the NAM [Ruzmaikin et al., 2004].

[15] The SST anomalies associated with the NAO show a meridional tripole pattern: cool north of $55^{\circ} \mathrm{N}$, warm in $20-$ $55^{\circ} \mathrm{N}$ band, and cool south of $20^{\circ} \mathrm{N}$ (positive phase of the NAO). The sign of this anomaly is opposite in the negative phase of the NAO [Seager et al., 2000]. During the positive (negative) phase of the NAO an anomalous upper tropospheric descending (ascending) airflow prevails in equatorial eastern Africa [Wang, 2002]. This airflow corresponds to drier (wetter) conditions over Lake Victoria and Lake Tana. It is interesting that the NAM was predominantly negative during the Maunder Minimum [Ruzmaikin et al., 2004] implying wetter conditions for equatorial Africa. This result is in agreement with the correlation between the Lake Victoria (and Lake Naivasha) levels and the solar variability in this period [Stager et al., 2005]. The 1000-year long record analyzed by Stager et al. [2005] shows marked correlation between the lake levels and solar variability (proxied by the atmospheric radiocarbon). Also a strong correlation between the atmospheric radiocarbon variations caused by solar variability and the levels of a small equatorial lake Naivasha (Kenya) was found [Verschuren et al., 2000]. Co-occurrence of lake level rises with minima of solar variability [see Stager et al., 2005, Figure 4] continues back in time overlapping with the Nile records used in our paper.

\section{Conclusions}

[16] Low-frequency 88-year variation is present in solar variability and the Nile water records during the same time period (622-1470 A.D.). The 11-year cycle is seen in highwater level variations, but it is damped in the low-water anomalies, apparently because of the influence of lakes and swamps at the start of the White Nile. On the basis of this finding we suggest the following possible link between solar variability and the Nile: (1) Solar UV variations act in the stratosphere to modulate the Northern Annular Mode (NAM); (2) The NAM's sea level manifestation (NAO) affects the air circulation over Atlantic and the Indian Oceans during high levels of solar activity; (3) Variations of this air circulation influence rainfall in eastern equatorial Africa at the Nile sources. At high solar activity, the air is descending there and conditions are drier, with the opposite effect occurring at low solar activity. Further investigations of this link will shed more light on the connection between the Sun's variability and the Nile.

[17] Acknowledgments. We thank the reviewers for critical and helpful comments. We are grateful to Don Percival for providing the Nile data. We also thank the participants of the SORCE 2005 meeting and of Y. Yung's seminar at Caltech for helpful discussions of the results presented in this paper. A.R. thanks N. Huang and P. Flandrin for helpful advice on the application of the EMD. This research was carried out in part at the Jet Propulsion Laboratory, California Institute of Technology, under a contract with NASA. Y.L.Y. was supported by NASA grant NNG04GN02G to the California Institute of Technology.

\section{References}

Baldwin, M. P., and T. J. Dunkerton (1999), Propagation of the Arctic Oscillation from the stratosphere to the troposphere, J. Geophys. Res. $104,30,937-30,946$.

Bell, B. (1970), The oldest records of the Nile floods, Geogr. J., 136, $569-573$.

Black, E., J. Slingo, and K. R. Sperber (2003), An observational study of the relationship between excessively strong short rains in coastal East Africa and Indian Ocean SST, Mon. Weather Rev., 131, 74-94.

Cess, R. D., and P. M. Udelhofen (2003), Climate change during 19851999: Cloud interactions determined from satellite measurements, Geophys. Res. Lett., 30(1), 1019, doi:10.1029/2002GL016128.

Cook, E. R., R. D. Darrigo, and K. R. Briffa (1998), A reconstruction of the North Atlantic Oscillation using tree-ring chronologies from North America and Europe, Holocene, 8, 9-17.

De Putter, T., M.-F. Loutre, and G. Wansard (1998), Decadal periodicities of Nile River historical discharge (A. D. 622-1470) and climatic implications, Geophys. Res. Lett., 25, 3193-3196.

Feder, J. (1988), Fractals, Springer, New York.

Feynman, J. (1988), Solar geomagnetic and auroral variability observed in the historic record, in Secular Solar and Geomagnetic Variations in the Last 10000 Years, edited by A. W. Wolfendale, pp. 141-159, Springer, New York.

Feynman, J., and P. F. Fougere (1984), Eighty-eight year periodicity in solar-terrestrial phenomena confirmed, J. Geophys. Res., 89, 3023-3027.

Flandrin, P., and P. Goncalves (2004), Empirical mode decompositions as data-driven wavelet-like expansions, Int. J. Wavelets Multiresolut. Inf. Process., 2, 477-496.

Gilman, D. L., F. J. Fuglister, and J. M. Mitchell Jr. (1963), On the power spectrum of "red noise," J. Atmos. Sci., 20, 182-184.

Hameed, S. (1984), Fourier analysis of Nile flood levels, Geophys. Res. Lett., 1, 843-845.

Hameed, S., and J. N. Lee (2005), A mechanism for Sun-climate connection, Geophys. Res. Lett., 32, L23817, doi:10.1029/2005GL024393.

Huang, N. E., Z. Shen, S. R. Long, M. C. Wu, H. H. Shih, Q. Zheng, N.-C. Yen, C. C. Tung, and H. H. Liu (1998), The empirical mode decomposition and the Hilbert spectrum for nonlinear and non-stationary time series analysis, Proc. R. Soc. London, Ser. A, 454, 903-995.

Hurrel, J. M. (1996), Influence of variations in extratropical wintertime teleconnections on Northern Hemisphere temperature, Geophys. Res. Lett., 23, 665-668.

Hurst, H. E. (1952), The Nile, 326 pp., Constable, London.

Kodera, K. (2003), Solar influence on the spatial structure of the NAO during the winter 1900-1999, Geophys. Res. Lett., 30(4), 1175, doi:10.1029/2002GL016584.

Kondrashov, D., Y. Feliks, and M. Ghil (2005), Oscillatory modes extended Nile River records (A.D. 622-1922), Geophys. Res. Lett., 32, L10702, doi:10.1029/2004GL022156.

Lean, J., and D. Rind (1998), Climate forcing by changing solar radiation, J. Clim., 11, 3069-3094.

Limpasuvan, V., and D. L. Hartmann (2000), Wave-maintained annular modes of climate variability, J. Clim., 13, 4414-4429.

Loutre, M.-F., A. Berger, P. Bretagon, and P.-L. Blanc (1992), Astronomical frequencies for climate research at decadal to century time scale, J. Clim Dyn., 7, 181-194.

Mistry, V. V., and D. Conway (2003), Remote forcing of East African rainfall and relationship with fluctuations in levels of Lake Victoria, Int. J. Climatol., 23, 67-89. 
Nicholson, S. E. (2000), The nature of rainfall variability over Africa on time scales of decades to millennia, Global Planet. Change, 26, 137-158.

Ogi, M., K. Yamazaki, and Y. Tachibana (2003), Solar cycle modulation of the seasonal linkage of the North Atlantic Oscillation (NAO), Geophys. Res. Lett., 30(22), 2170, doi:10.1029/2003GL018545.

Rind, D. (1996), The potential for modeling the effects of different forcing factors on climate during the past 2000 years, in Climate Variations and Forcing Mechanisms of the Last 2000 Years, edited by P. D. Jones, R. S. Bradley, and J. Jouzel, pp. 563-582, Springer, New York.

Ruzmaikin, A., and J. Feynman (2002), Solar influence on a major mode of atmospheric variability, J. Geophys. Res., 107(D14), 4209, doi:10.1029/ 2001JD001239.

Ruzmaikin, A., J. Feynman, X. Jiang, D. Noone, A. Waple, and Y. Yung (2004), The pattern of Northern Hemisphere temperature during prolonged periods of low solar output, Geophys. Res. Lett., 31, L12201, doi:10.1029/2004GL019955.

Seager, R, Y. Kushnir, M. Visbeck, N. Naik, J. Miller, G. Krahmann, and H. Cullen (2000), Causes of Atlantic Ocean climate variability between 1958 and 1998, J. Clim., 13, 2845-2862.

Sene, K. J., E. L. Tate, and F. A. K. Farquharson (2001), Sensitivity studies of the impact of climate change on White Nile flows, Clim. Change, 50, $177-208$

Siscoe, G. L. (1980), Evidence in the auroral record for secular solar variability, Rev. Geophys., 18, 647-668.

Stager, J. C., D. Ryves, B. F. Cumming, L. D. Meeker, and J. Beer (2005), Solar variability and the levels of Lake Victoria, East Africa, during the last millennium, J. Paleolimnol., 33, 243-251.
Stuiver, M., and T. F. Brauzanias (1989), Atmospheric ${ }^{14} \mathrm{C}$ and centuryscale solar oscillations, Nature, 338, 405-408.

Tate, E., J. Sutcliffe, D. Conway, and F. Farquharson (2005), Water balance of Lake Victoria: Update to 2000 and climate change modeling to 2100 , Hydrol. Sci., 49, 563-574.

Thompson, D. W. J., and J. M. Wallace (1998), The Arctic Oscillation signature in the wintertime geopotential height and temperature fields, Geophys. Res. Lett., 25, 1297-1300.

Toussoun, J. D. (1925), Memoire sur l'histoire du Nil, Mem. Inst. Egypte, $18,366-404$

Verschuren, D., K. R. Laird, and B. F. Cumming (2000), Rainfall and drought in equatorial East Africa during the past 1,100 years, Nature, $403,410-413$.

Wang, C. (2002), Atlantic climate variability and its associated atmospheric circulation cells, J. Clim., 15, 1516-1536.

Wu, Z., and N. E. Huang (2004), A study of the characteristics of white noise using the empirical mode decomposition method, Proc. R. Soc London, Ser. A, 460, 1597-1611.

J. Feynman and A. Ruzmaikin, Jet Propulsion Laboratory, 4800 Oak Grove Drive, Pasadena, CA 91109, USA. (aruzmaik@pop.jpl.nasa.gov)

Y. L. Yung, Department of Geological and Planetary Sciences, California Institute of Technology, California Boulevard, Pasadena, CA 91125, USA. (yly@gps.caltech.edu) 